\title{
DOGMÁTICA PENITENCIARIA Y REALIDADES ACTUALES \\ EN EL DERECHO PENITENCIARIO HONDUREÑO
}

\author{
PENITENTIARY DOGMATICS AND CURRENT REALITIES \\ IN THE HONDURAN PENITENTIARY LAW
}

\begin{abstract}
Raúl Gilberto Rivas Paniagua ${ }^{1}$
DOI: https://doi.org/10.5377//rd.v40i1.8905

\section{RESUMEN}

En el presente artículo se hace un análisis de los aspectos dogmáticos relevantes de la ciencia penitenciaria, los mismo con el objetivo de entender cómo ha ido evolucionando la dogmática penitenciaria y en algunos aspectos de qué manera se ha establecido del porque se plantea que la pena ha entrado en decadencia por los múltiples factores que presenta la ejecución de la pena privativa de libertad, así mismo, se plantea una valoración crítica del lento avance del Estado de Honduras en enmendar los problemas estructurales ya denunciados en el informe de la Comisión Interamericana de Derechos Humanos.
\end{abstract}

PALABRAS CLAVE: Derecho Penal, Derecho Penitenciario, ejecución de la pena privativa de Libertad, pena, cárcel.

\begin{abstract}
In the present article an analysis of the dogmatic aspects relevant to the penitentiary science is analyzed, the same one with the objective to understand how the penitentiary dogmatic has evolved and in some aspects in what way it has been established of because It raises that the penalty has come into decline because of the many factors that the execution of the custodial sentence presents itself, it raises a critical assessment of the slow progress of the state of Honduras in amending the structural problems already denounced In the report of the Inter-American Commission on Human Rights.
\end{abstract}

KEYWORDS: Criminal Law, Prison Law, enforcement of the custodial sentence, penalty, and prison.

Fecha de recepción: 07 de mayo del 2019

Fecha de aprobación: 08 de julio del 2019

\footnotetext{
${ }^{1}$ Master en Derecho Penal, Universidad de Sevilla, España. Profesor de Derecho Penitenciario.

Correo: paniagua raul@yahoo.es
} 


\section{INTRODUCCION}

El tema carcelario como se ha denominado representa un dolor de cabeza para el Estado, la conducción o manejo de los centros penitenciarios no es cosa fácil, más cuando al endógeno y al exógeno de los mismo opera la corrupción provocando enormes daños, tanto a la imagen del Estado, como a los fines constitucionales de la pena.

Entre distintos puntos, los aspectos señalados anteriormente son los que han llevado a determinar de la decadencia en que ha entrado la pena como sistema punitivo del delito, dentro del tema penitenciario hasta cierto punto dentro de los foros de abogados son pocos los investigadores que le dedican cierto espacio de investigación a dicho tema, y dentro de la sociedad este tema provoca rechazo porque se refiere a cárcel, delitos, personas peligrosas, y sobre este mundo carcelario se ha provocado una especie de etiquetamiento negativo.

Basta con ahondar un poco en la investigación para darse cuenta de que este tema dogmáticamente es amigable, interesante, porque el mismo plantea una serie de temas importantes de como se ha ido desarrollando esta materia, como por ejemplo, la evolución de la pena desde épocas como en el antiguo régimen, a medida que poco a poco se fue humanizando, así mismo, tenemos el sistema progresivo como cumplimiento gradual de la pena con sus características especiales, entre muchos otros temas interesantes que han marcado la evolución y el estudio del Derecho Penitenciario.

Los postulados o fines resocializadores han entrado en una decadencia profunda por el tema de que no se ven los avances positivos de las personas en prisión, se habla hasta el punto de sustituir la pena de prisión por sistemas más avanzados de ejecución de la pena privativa de libertad, en vista de que el encierro no está dando resultados que se esperan positivos, es por ello que se habla de una cárcel telemática con nuevos postulados y con una nueva forma de cumplir la pena privativa de libertad, abandonando la prisión o el encierro, sobre todo en aquellos casos de penas cortas o de mediano plazo.
El presente artículo representa un breve estudio dogmático del nacimiento del Derecho Penitenciario $\mathrm{y}$ cómo ha evolucionado, $\mathrm{y}$ un estudio aproximado de lo que representa la Ley del Sistema Penitenciario Nacional, lo cual es una Ley con extraordinarios estándares de protección de los Derechos Humanos, con altos estándares para llevar a cabo una perfecta resocialización del privado de libertad, pero resulta que hay algunas incompatibilidades, y es que la Ley del Sistema Penitenciario de Honduras, no va de acorde a la voluntad del Gobierno para echar a andar una Ley de vanguardia, es decir, que para adecuar la voluntad del Gobierno a esta Ley, se ocupa un enorme esfuerzo, un buen presupuesto, se ocupa voluntad, pero una voluntad verdadera, no a medias tintas, si bien es cierto, se han construido cárceles, pero como dice la Comisión Interamericana de Derechos Humanos, eso solo son paños tibios, en verdad se ocupa una política penitenciaria más fuerte, más eficaz, las deficiencias del sistema carcelario del pasado, aún siguen vigentes causando mucho daño

Diversas instituciones de protección de los Derechos Humanos de los privados de libertad en Honduras, constantemente realizan recomendaciones que deben cumplir las autoridades penitenciarias para llevar a cabo una apropiada ejecución de la pena privativa de libertad, lo cual estas deben tomarse en consideración de manera inmediata para ir preparando al recluso para la vida en libertad, por el motivo de que las condiciones carcelarias de los centros penitenciarios en Honduras, vulneran los Derechos Humanos constantemente.

\section{ASPECTOS RELEVANTES QUE HAN MARCADO EL CARÁCTER DE CIENCIA PENITENCIARIA.}

La ciencia penitenciaria no es una ciencia que nació de la noche a la mañana como ciencia, toda ciencia para llegar a ser ciencia debe afrontar un proceso profundo de investigación para concretarse como tal, el nacimiento de la ciencia penitenciaria podríamos decir que es relativamente joven, en primer lugar, esta ciencia no nació como ciencia penitenciaria, sino que en un primer momento fue denominada como 
penología, y estaba adscrita a la ciencia penal, así la definió Francis Lieber en 1838, y que se ocupaba del castigo del delincuente ${ }^{2}$, ya que tradicionalmente el castigo del delincuente siempre ha sido el encierro, la cárcel.

El avance o evolución de esta ciencia para concretarse como ciencia penitenciaria no es sino hasta 1933 y 1935 donde dos profesores italianos fueron los precursores para determinar que la penología no dependía de la ciencia penal, sino que es una ciencia autónoma que se vale por sus propios principios y fundamentos que se caracteriza como ciencia penitenciaria, en ese sentido, el Profesor Giovanni Novelli publica un artículo denominado " $\mathrm{L}$ ' autonomía del Diritto penitenziario" posteriormente el profesor Francesco Siracusa publica otro artículo bajo el nombre de "Instituzioni di Diritto Penitenziario", ${ }^{3}$ podríamos decir que aquí es el nacimiento de la ciencia penitenciaria como ciencia, a partir de este momento comenzó un tsunami del desarrollo del Derecho Penitenciario, esto quiere decir que la ciencia penitenciaria se desmiembra de la ciencia penal, y da punto para iniciar el estudio de la ciencia penitenciaria de manera autónoma, es decir, se comienza un estudio separado del Derecho Penal, y en ese término evolutivo, inician los estudios para concretizar aún más el carácter de ciencia penitenciaria, inicia el objeto de estudio, inicia el debate para la creación del estudio jurisdiccional, para crear una Ley propia para el manejo de los centros penitenciarios, creación de los propios principios en que fundamentarse, y así buscar una autonomía más sólida en que cimentar el carácter de ciencia.

No cabe duda que la evolución de esta ciencia está bien marcada por los estudios de especialistas que han llevado a cabo el desarrollo dogmático de los estudios penales, pero así mismo, a esta evolución se le han formulado críticas, dando a entender que no es una ciencia, por establecer que contiene normas de distintas ramas, como decir, que posee para su desarrollo normas de carácter administrativo,

\footnotetext{
${ }^{2}$ Rodríguez Magariños, F.G. "El Derecho Penitenciario”. En R. V, Martínez (Dir.) y otros, Derecho Penitenciario, pág. 34, Valencia, Tirant Lo Blanch

${ }^{3}$ Rodríguez Magariños, F.G. “El Derecho Penitenciario” óp. Cit. p. 34.
}

normas de carácter procesal, pero en ese sentido se ha establecido que ese debate, ya es arcaico y que la doctrina mayoritaria reconoce al Derecho Penitenciario como ciencia.

Como se estableció previamente, que una vez que se le dio el carácter de autonomía, pues dio pie para iniciar un estudio más profundo en la cual a raíz de esos puntos, se comenzaron a abrir cátedras de Derecho Penitenciario, dieron inicios conferencias, revistas de investigación, por ejemplo, toda ciencia, prima facie, debe partir de principios para encontrar un formal fundamento en qué desarrollarse.

La ciencia penitenciaria ha desarrollado una serie de principios para fundamentar el estudio del Derecho Penitenciario, entre ellos tenemos, el principio de legalidad, que es el principio por excelencia en que se fundamenta todo el ordenamiento jurídico, establece que las sanciones penales que se ejecutan a un privado de libertad, deben estar previamente determinadas en Ley, es decir, que tenga el carácter de norma jurídica.

De igual manera, como elemento determinante y que en algunos ordenamientos tiene carácter constitucional, lo constituye el principio de resocialización ${ }^{4}$ el cual busca, una especie de preparación para la vida en libertad del condenado a través del tratamiento y del régimen penitenciario, es así como se va configurando el carácter de ciencia, pero eso no es todo, a esto hay que sumarle otros puntos importantes, como por ejemplo los que señala el Profesor Borja Mapelli relativas a la evolución del Derecho Penitenciario, en primer lugar establece que la evolución de esta materia se debe al nacimiento de la pena privativa de libertad, y al III Congreso Internacional de Derecho Penal, celebrado en Palermo Italia en 1932, donde se le dio autonomía a la ciencia penitenciaria, en segundo lugar, se destaca el desarrollo doctrinal sobre lo que escribió Novelli y otros autores en cuanto a la autonomía del Derecho Penitenciario, y por último, lo marco un movimiento legislativo en distintos países de Europa, entre ellos, España.

\footnotetext{
${ }^{4}$ Subijana Zunzunegui, I. J., (2005) El Juez en la ejecución de las penas privativas de libertad. Revista Electrónica de Ciencia Penal y Criminología, RECPC07-11, ISSN 1695-0194, pág. 7-8.
} 
En el primer elemento destaca sobre la pena privativa de libertad que viene a nacer aproximadamente en el siglo XVIII, pero que luego destaco con más fuerza a finales del Siglo XIX, y Siglo XX hasta lo que tenemos hoy de lo que es la cárcel, dentro de esa misma evolución inicio un debate dialectico profundo a partir del artículo de Novelli y otros autores que comenzaron a desarrollar esta ciencia, y era tanto el debate dialectico que se había planteado, que los legisladores o los ordenamiento jurídicos no se quedaron atrás, y es así como comenzaron en los parlamentos a debatir el tema, en vista de que el tema carcelario supondría castigo, pero más que eso, supondría violación de derechos y garantías, los cuales era necesario adaptar la legislación a los estudios de los derechos humanos, buscando la eficacia que representan los fines resocializadores de la pena.

\section{I. SISTEMA PROGRESIVO I N D I V I D UA L I Z A C I O N T R A T A M I E N T O}

Dentro de los estudios de la ciencia penitenciaria, hablando desde el punto de vista dogmático, ha sido una ciencia que ha evolucionado, está claro, que toda ciencia que evoluciona tiene sus pros y sus contras, que de alguna $u$ otra forma pueden representar en el futuro un análisis de acuerdo a la situación que se pueda presentar en determinado momento, porque, así como evoluciona una ciencia, así mismo se puede estancar.

Un punto sumamente importante que marco la ciencia penitenciaria y su evolución ha sido el sistema progresivo, sobre la cual parte la mayoría de los ordenamientos jurídicos que siguen un derecho continental europeo, lo que sí está claro, es que el sistema progresivo representó un avance importante en el tema carcelario, y tiene un significado preponderante en la etapa de la ejecución de la pena, $\mathrm{y}$ es que el condenado a cumplir una pena privativa de libertad a lo interno del centro penitenciario debe cumplir una misión, quedaron el olvido aquellos patrones tradicionales de cumplimiento de la pena, donde el privado de libertad, más que una persona, era un objeto y en el cual esos sistemas tradicionales de ejecución de la pena quedaron en el pasado y uno de los castigos que represento la pena era el castigo corporal.

No obstante, al evolucionar dicho sistema el tema se ha vuelto tan importante que se ha marcado en la mayoría de las legislaciones de América, y es el Sistema Progresivo que en primera línea nació en Europa, dándole un papel participativo al privado de libertad en el cumplimiento de la pena, este sistema está compuesto de periodos o fases, esto quiere decir, que el cumplimiento de la pena estaba basado en el cumplimiento gradual y progresivo de la condena, el primer periodo del sistema progresivo lo representa un aislamiento absoluto, esto es, que al ingresar a prisión el condenado era destinado a un aislamiento E celular absoluto $^{5}$, esto significa que de entrada al centro penal, se debía cumplir un plan programático en aislamiento total, tanto diurno como nocturno, este periodo estaba destinado a personas altamente peligrosas que no se pueden adaptar a otros regímenes más flexibles.

Luego como el sistema es progresivo en determinado tiempo se debe avanzar en grados hacia otra etapa o periodo de tiempo, así mismo, a medida que transcurría el tiempo en prisión y el condenado iba cumplimiento su estancia en la misma, se le iban concediendo algunos beneficios penitenciarios, a este se le puede considerar el segundo periodo progresivo, en este periodo era o es más activo que el primer periodo, este es más dinámico, y el tercer periodo digamos lo comprende la libertad en preliberación o como lo llamaba el Coronel Montesinos libertad intermedia ${ }^{6}$, es decir, que el privado entra en un proceso de desprisionizacion, es decir, abandonar todas aquellas prácticas o costumbres carcelarias que adopto el privado de libertad al ingresar y convivir en la prisión durante un largo tiempo, con la libertad

${ }^{5}$ Fernández García, J., El Derecho Penitenciario. Concepto. En Berdugo Gómez de la Torre, Zuniga Rodríguez (Coords) p. 115, Salamanca, Colex.

${ }^{6}$ Clases Magistrales, "La Ejecución de la Pena Privativa de Libertad" Universidad de Sevilla, 2015. 
en pre-liberacional, entrara en un nuevo proceso de adopción de su personalidad como persona, y abandonar la personalidad de preso al entrar en contacto con el mundo exterior.

Luego que pasase un tiempo determinado en cuanto al sistema progresivo, nace lo que se denomina en España la individualización científica, que es lo mismo la individualización del tratamiento en Honduras, este sistema procede de los modelos progresivos basados en criterios rígidos ${ }^{7}$ de cumplimiento de pena, el sistema de individualización del tratamiento significa que el tratamiento penitenciario, se llevara a cabo tomando en consideración distintos elementos de la persona que ingresa a prisión, como ser, las condiciones personales, condiciones criminológicas, situación jurídica de acuerdo a las respectivas evaluaciones que realice el Consejo Técnico Interdisciplinario ${ }^{8}$, esto es, que se abandonaron los sistemas clásicos de ejecución de pena, por el de la individualización subjetiva acorde a las necesidades personales, individuales que presenta cada condenado ${ }^{9}$, cuando entra en escena el sistema de individualización científica del tratamiento, es cuando dieron inicios los Consejos Técnicos Interdisciplinarios, compuestos por una serie de profesionales, encargados de evaluar a los condenados y clasificarlos en algunos de los regímenes cerrados, ordinarios o abiertos.

\section{PROBLEMAS Y EFECTOS RELEVANTES QUE PRESENTA LA EJECUCION DE LA PENA PRIVATIVA DE LIBERTAD. NUEVAS ALTERNATIVAS A LA CARCEL.}

Como se ha planteado aquí el arma fundamental con que cuenta el Derecho Penal para hacerle frente al delito, es la pena, más modernamente ahora las medidas de seguridad, pero en esencia es la pena la que más se aplica para combatir el crimen, en casos

\footnotetext{
${ }^{7}$ Montero Hernanz, T. "El Derecho Penitenciario”. En R. V, Martínez (Dir.) y otros, Derecho Penitenciario, pág. 34, Valencia, Tirant Lo Blanch

${ }^{8}$ Véase con más referencia ver artículo 106 del Reglamento General de la Ley del Sistema Penitenciario Nacional de Honduras.

${ }^{9}$ Cuello Contreras, J., Mapelli Caffarena, B., (2015) Curso de derecho penal PG, Madrid, Tecnos.
}

especiales, se aplican las medidas de seguridad, la sanción o consecuencia de la comisión de un delito es la pena, y esta consiste en la privación de algún derecho que en esencia es la libertad ${ }^{10}$.

Cabe resaltar que las teorías de la pena a través del transcurso del tiempo han ido evolucionando en sus fundamentos y principios, los que se conocen hoy como fines de la pena, pero también puede decirse que hay otros fundamentos que las justifican, como los políticos y los socio-criminológicos ${ }^{11}$, cada uno representa una función para legitimarse en un Estado de Derecho dentro de una sociedad.

Como se ha planteado, el derecho, la dogmática penal, las ciencias sociales no son ciencias estáticas, son ciencias dinámicas y por ende constantemente deben evolucionar buscando un avance para una mejor aplicación de tales criterios.

Así mismo, la pena ha sido objeto constante de estudio dándole diferentes significados, hay que tener clara una cosa, la evolución o involución de las sanciones penales en su modelo de ejecución va a depender del modelo de Estado que represente el poder público, he ahí podríamos tener un primer problema con efectos nocivos que desencadenan enormes perjuicios para un Estado Constitucional, todo dependerá a los intereses a que juegue el Estado, y a los fines que pretenda darle a la pena ${ }^{12}$, esto significara la tendencia ideológica hacia donde se oriente el Estado, y la preponderancia que pretenda darle cumplimiento y desarrollo a la pena privativa de libertad, hay una característica importantes que resaltar, la evolución del Estado debe ser integral, en todos los sentidos, pero con el hecho de que un Estado de ser un Estado de Derecho en toda su plenitud, pase a ser un Estado represor en la ejecución de la pena, sin la más mínima garantía de respeto del ordenamiento jurídico de una sociedad, de manera automática entre distintos

\footnotetext{
${ }^{10}$ Carbonell Mateu, J.C. (1999) Derecho Penal Concepto y Principio Constitucionales, Valencia, Tirant Lo Blanch.

${ }^{11}$ Polaino Navarrete, M., (2015) Lecciones de Derecho Penal PG, Madrid, Tecnos.

${ }^{12}$ Borja Jiménez, E, (2011) Curso de Política Criminal, Valencia Tiran Lo Blanch.
} 
puntos, el modelo de ejecución de la pena de manera automática también entrara en un proceso involutivo, y esto desembocaría en los fines o principios en que se fundamenta el Derecho Penitenciario.

A este planteamiento se suma el Profesor Mir Puig, y señala que el Derecho a sancionar se fundamenta en distintas concepciones políticas ${ }^{13}$, se colige de los anteriores planteamientos, del modelo de Estado o de la ideología al que pertenece el partido político en el poder, no podemos obviar que los partidos políticos con tendencia ideológica de derecha, son los partidos que más utilizan la pena privativa de libertad, orientan sus campañas electorales políticas de mano dura, de cero tolerancia, y los partidos de izquierda utilizan en sus campañas electorales políticas más humanistas y menos represoras, con tendencia a mejorar el sistema de administración de centros penales y de la ejecución de la pena ${ }^{14}$, esto significa que si un Estado es lesivo con una política criminal represiva, no resocializadora, no habrán resultados positivos, haciendo solo énfasis en la retribución.

La pena privativa de libertad, como señale supra, ha sido y sigue siendo objeto de estudio, lo que sí ha quedado evidenciado es el fracaso al que ha llegado la ejecución de la pena privativa de libertad, esto obedece a los exiguos resultados que ha presentado la misma, y la masiva utilización de la pena privativa de libertad para sancionar delitos.

La pena o las sanciones penales han sido vista desde distintas perspectivas, es decir, que la doctrina no se ha quedado estática en cuanto al análisis de la pena, y a medida que ha transcurrido el tiempo se le han ido dando distintas connotaciones, como por ejemplo, el nacimiento del sistema monista, el sistema dualista, en esencia cada uno con sus postulados, hasta que fueron siendo abandonados cuando apareció el sistema vicarial como un sistema de sanción punitiva totalmente diferenciada a la hora de su aplicación con los postulados anteriores, desde esa perspectiva, se plantean los diferentes sistemas de sanción penal, buscando darle a la pena distintos sentidos, más

${ }^{13}$ Mir Puig, S. (1998) Derecho Penal Parte General, Barcelona, Reppertor. ${ }^{14}$ Borja Jiménez, E, (2011) Curso de Política Criminal. Óp. Cit p. 80-81. que solo castigar, sino también ser respetuosos de la dignidad humana y ser respetuosos del Estado de Derecho, y de los principios político-criminales del derecho penal y penitenciario. Han surgido distintas formas de resolución de las conductas delictivas, en vista de que la pena no está resolviendo los problemas sociales, en vez de resolverlos, más bien crea más problemas sociales por los problemas estructurales que presentan los establecimientos penitenciarios a su interior y la poca importancia que muestran los Gobiernos en cuanto a la resocialización dando lugar a la reincidencia delictiva.

En cuanto a una moderna forma de solución de problemas con connotaciones penales es la reparación del daño a la víctima como una vía de solución de delitos, siendo distintos profesores de distintas nacionalidades quienes desarrollaron el Proyecto Alternativo de la Reparación, entre ellos, los profesores alemanes Hans Joachim Hirsch y Claus Roxin $^{15}$, esto no es más que una atenuación de la pena, lo que se busca con este innovador sistema, es otro medio de sanción que no sea la pena, como se ha planteado la decadencia de la pena y su ejecución entonces se han buscado otras alternativas de hacer más determinantes los fines de la pena concretamente la prevención especial.

Al inicio de este articulo plantee lo que significa las prisiones para los Gobiernos, y no son más que un problema, se llevan un alto presupuesto del Estado y los resultados son exiguos, como popularmente se dice en Honduras, "son tendaladas de personas que entran a diario en prisión en Honduras", ese número de persona provoca un gasto considerable del presupuesto general de la república, aunado a ello, los índices de criminalidad son altos, por tanto, estas aristas provocan un efecto negativo en la ejecución de la pena, tantas personas necesitadas de resocialización y dentro de los centros penitenciarios el personal al interno del mismo no se ve en la capacidad de atender todas esas personas necesitadas de un tratamiento penitenciario progresivo.

Por ejemplo, podríamos decir que algunos centro ${ }^{15}$ Polaino Navarrete, M., (2015) Lecciones de Derecho Penal PG, óp. Cit., p. 38. 
penitenciario únicamente cuenta con 3 o 4 psicólogos, estos profesionales deben atender una alta población penitenciaria, los cuales no se dan abasto para atenderlos a todos, provocando esto, ineficacia en los fines resocializadores, las principales víctimas de esto son los propios privados de libertad que no cuentan con programas resocializadores adecuados para lograr su reinserción en la sociedad, y esto además de ser un problema grave para el Estado crea efectos nocivos en los fines constitucionales resocializadores, y como se han planteado que los resultados no son positivos, de tal manera que se habla del fracaso de los fines resocializadores.

Hay quienes siguen manteniendo la tesis del planteamiento resocializador a pesar de su decadencia y de sus resultados deficientes en la ejecución de la pena, esto quiere decir, que se sigue manteniendo la pena como medio de sanción de delito, el aplicar la pena no lleva a ninguna solución más que separar de la sociedad al delincuente dando cumplimiento a los fines retributivos de la pena que eran los que se aplicaban en la era del antiguo régimen. Modernamente en la evolución de la pena se plantearon los fines resocializadores, como la prevención general y sobre todo la prevención especial.

La pena lo que busca más concretamente es la eficiencia de la prevención especial que se sitúa sobre el propio autor del delito, a partir de los años 70's, se caracterizó por una creciente devaluación de los postulados o fines resocializadores de la pena ${ }^{16}$, dando lugar al fracaso de la pena, los centros penitenciarios no cuentan con la administración penitenciaria adecuada acorde al volumen de privados de libertad que se encuentran y que van entrando a los centros penitenciarios.

Esto ha conllevado a la decadencia de la pena privativa de libertad, esta decadencia de manera estricta tiene efectos negativos sobre el propio privado de libertad, y de manera laxa, tiene efectos negativos sobre la propia sociedad, en vista de que una vez este privado cumpliendo la pena privativa de libertad,

${ }^{16}$ Mapelli Caffarena, B. (2004) Perspectivas actuales de la pena privativa de libertad con especial referencia a la población reclusa extranjera, Revista Centroamericana, Justicia penal y sociedad. Nro. 18, 139-160. debe excarcelarse, y esto conlleva a que una persona no resocializada volverá a cometer nuevamente infracciones delictivas, porque dentro de la prisión no se resocializó, y el efecto multiplicador en sentido negativo es que esta persona vuelva a delinquir, y nuevamente regrese a prisión convirtiendo esto en un círculo vicioso, y en una batalla de nunca acabar, no se le asegura a la sociedad que el recluso sale reinsertado, desde una perspectiva eminentemente penitenciaria las cárceles constituyen un centro de problemas, la cárcel tradicional no es mejor lugar para la realización de la rehabilitación del condenado, es más, fomenta el crimen, y produce la desocialización de la persona incapacitándola de la sociedad ${ }^{17}$.

Después de todo el planteamiento anterior en cuanto a la crisis de la pena y del modelo de ejecución, la dogmática y la doctrina ha tenido que trabajar en cuanto a nuevos planteamientos de solución de los problemas en cuanto a la ejecución de la pena, algunos ya planteados supra, como la reparación a la víctima. A medida que ha transcurrido el tiempo llevar a cabo una ejecución de la pena se ha complicado en vista de que la entrada a prisión de personas ha ido en aumento constante y esto satura las prisiones de personas que se han visto envueltas en problemas con la justicia, quien está al frente de la ejecución de la pena es la administración penitenciaria compuesta por los Consejos Técnicos Interdisciplinarios donde se albergan profesionales en distintas materias para llevar un tratamiento penitenciario de acuerdo a las condiciones personales de cada privado de libertad.

El Juez de Ejecución de la pena, representa solamente los ojos vigilantes de ese tratamiento penitenciario, es un actor que únicamente esta para vigilar y controlar el tratamiento penitenciario cuando sea necesario, cuando haya un abuso por parte de quienes están encargados de llevar a cabo el tratamiento, el estudio de cada privado de libertad lleva un tiempo determinado.

No debemos olvidar que la población penitenciaria no son mil, ni cinco mil personas a quienes corresponde

${ }_{17}$ Del Rio Fernández, L., (2016) Manual de Derecho Penitenciario, Agencia Española de Cooperación Internacional, Tegucigalpa, Ediciones San Miguel. 
evaluar, sino que la población penitenciaria de Honduras sobrepasa las veinte mil personas, y evaluar todo ese grupo de reclusos no es cosa sencilla, y el personal penitenciario es exiguo para llevarlo a cabo, es decir, que en términos de recursos humanos y recursos económicos no alcanzan para ejecutar esa ardua y enorme tarea, y todo esto desemboca en el fracaso de los programas resocializadores, y podríamos decir que el fracaso va en dos vías, primero en que la cárcel como medio de intimidación no ha provocado los resultados esperados de hacer un alto en la delincuencia, en ese sentido, se expresa, que modelo de ejecución clásica se encuentra sumida en una profunda crisis, llegándose a plantear que la prisiones son un factor criminógeno ${ }^{18}$, y en segundo lugar lo que hemos venido hablando del fracaso resocializador en sus fines.

Ante la situación descrita anteriormente ha aparecido como una especie de solución al fracaso de la resocialización, lo que han denominado la cárcel electrónica, cárcel virtual, cárcel telemática o cárcel tecnológica, y no es más que aquella que se lleva puesto un grillete electrónico, o un collarín, con esta propuesta se iría abandonando la cárcel tradicional del encierro en un centro penitenciario, no debemos olvidar que esta es una propuesta que está en desarrollo, y que la cárcel tradicional tiene plena vigencia y que la primera se ha aplicado en algunos casos muy esporádicos, solamente es una propuesta a desarrollar como mecanismo alterno a la prisión física del recluso, no es algo que está desarrollado, a medida que pasa el tiempo va tomando fuerzas.

Para implementar este nuevo planteamiento deben pasar muchos años para poder ser implementada, algunos la han denominado la cárcel del futuro con nuevos modelos de vigilancia electrónica, con este sistema se deja de lado el encierro penitenciario lo cual haciendo un análisis sintético, la cárcel tradicional no ha respondido a las expectativas que se esperaron, hay un sector doctrinal a pesar de los resultados se muestra reacio con este nuevo modelo penitenciario electrónico. Este nuevo modelo es aquel que la persona condenada por delito, se le adhiriera ${ }^{18}$ Del Rio Fernández, L., (2016), Manual de Derecho penitenciario, óp. Cit. p. 81. a su cuerpo un sistema de control electrónico que constantemente envié información de su ubicación geográfica $^{19}$, se ha determinado que el componente electrónico a imponer, puede ser tobillera, brazalete, o un chip incrustado en el cuerpo no visualizable por las demás personas evitando en este último caso el señalamiento o etiquetamiento de la persona que porta un dispositivo electrónico de este tipo.

Este nuevo sistema penitenciario no solamente estaría reducido a la portación de un chip o un brazalete electrónico, sino que también el condenado estaría en la obligación en los casos que amerite el cumplimiento de otras obligaciones, supra establecí como modelo o alternativa el cumplimiento de ciertos requerimientos como la reparación del daño a la víctima, también un programa de terapias de comportamiento de respeto a la Ley.

Con este nuevo modelo llevaría al Estado a ahorrarse cantidades significativas de dinero, porque queda atrás el modelo penitenciario tradicional del encierro, solamente en alimentación se le ahorraría al Estado una suma considerable de dinero, en el ahorro de energía de los establecimientos penitenciarios, reduciría de manera sustantiva los problemas estructurales que presentan los centro penitenciarios tradicionales $^{20}$, y el efecto multiplicador, le podría ahorrar condenas a los Estados en los organizamos jurisdiccionales internacionales por violaciones masivas y constantes de los Derechos Humanos.

De igual manera y con mucha significancia no se vería de ninguna manera arraigada el efecto de la prisionizacion en el privado de libertad, con este nuevo modelo tendría efectos sumamente positivos para el cumplimiento de la pena buscando un nuevo ciudadano, un ciudadano ejemplar, buscando buenos ciudadanos que se sometan a las normas de que se deben adoptar en sociedad. Para el anterior planteamiento también debemos hacer un análisis en cuanto al nivel educativo de la persona que se va a someter a

\footnotetext{
${ }^{19}$ Deym, J., Crisis actual del sistema penitenciario y de la política penal. Recuperado de http://www.derecho.uba.ar/publicaciones/pensar-enderecho/revistas/2/crisis-actual-del-sistema-penitenciario-y-de-lapolitica-penal.pdf

${ }^{20}$ Deym, J., Crisis actual del sistema penitenciario y de la política penal. Óp. Cit. p. 253.
} 
un componente electrónico de este tipo y sumamente importante el grado de compromiso que va asumir la persona en cuanto al cumplimiento de la pena y del sometimiento del programa a cumplir, y esto nos lleva a pensar que hasta cierto punto no debe obviarse el cierre total del centro penitenciario tradicional, el cual albergaría a estas personas que no se someten al cumplimiento de las directrices de la cárcel electrónica y a todo su programa resocializador, el punto anterior es un tema discutible, para algunos una vez planteado el nuevo sistema penitenciario del modelo electrónico pueda dar lugar a cerrar definitivamente las prisiones, para otro sector doctrinal podría plantearse que no, y mantenerlo, o de desde otra perspectiva, una vez implementada la cárcel telemática, pueden diseñarse distintos programas de cumplimiento de la pena, estableciendo distintas etapas del programa, unos más rígidos que otros, se debe decir, que estos son planteamientos de lege ferenda desde un momento que no se ha implementado este sistema de manera total, pueden surgir otros planteamientos, y mejores.

Los orígenes de este nuevo sistema penitenciarios electrónico es anglosajón, dicho modelo se le conoce por algunos profesores como la cárcel del fututo, este mecanismo parte de la idea de que dicha cárcel electrónica, es un dispositivo que constantemente está emitiendo información de la persona que lo porta, tiene un sistema de alarma sumamente tecnológico, que cuando quien lo usa se está saliendo del espacio geográfico emite una alerta a una central que recepciona esa información, este dispositivo está en la libertad hasta de hacer una descarga eléctrica para controlar que no se violente las restricciones impuestas, de igual manera este sistema puede emitir información si en algún momento la persona consume algún tipo de drogas que le altere el sistema nervioso central $^{21}$.

Así las cosas, existe algún sector doctrinal que parte de la idea de que resocializar entre muros no es nada positivo, o que resocializar fuera de la sociedad no es nada viable para llegar a resultados concretos de acuerdo a la situación que se vive en un centro

\footnotetext{
${ }^{21}$ Clases magistrales de la ejecución de la pena privativa de libertad, Master en Derecho Penal, Universidad de Sevilla, España, Prof. Dr. Borja Mapelli Caffarena, noviembre 2015.
}

penitenciario, hay autores tan importantes dentro de la doctrina como Bettiol, García-Pablos, Muñoz Conde, miran la resocialización como un mito vacío de contenido, este último autor señala que no puede de manera voluntaria aceptarse un tratamiento por medios coercitivos ${ }^{22}$, en ese sentido, la cárcel telemática es más humana, es más económica, y soslaya la marginación social. ${ }^{23}$

\section{LEY DEL SISTEMA PENITENCIARIO HONDUREÑO CONFRONTADA CON LA REALIDAD DEL SISTEMA CARCELARIO EN HONDURAS Y CON EL INFORME DE LA CIDH}

Honduras aprueba en el año 2012, la Ley del Sistema Penitenciario Nacional (en adelante LSPN) según decreto 64-2012, publicada en el Diario Oficial la Gaceta, el lunes 3 de diciembre del 2012, Núm. 32, 990, lo cual la respectiva Ley en mención cuenta con su propio Reglamento, y es el Instituto Nacional Penitenciario (en adelante INP) quien tendrá a su cargo la organización, administración y funcionamiento de los centros penitenciarios a nivel nacional, así señalado en su artículo 7 de la respectiva Ley.

El Fundamento Constitucional de la creación del sistema carcelario y de la rehabilitación del privado de Libertad lo encontramos en el artículo 87 de la Constitución de la Republica ${ }^{24}$, que significa que a través de los establecimientos penitenciarios la sociedad se defenderá del delincuente sometiéndolo a una pena temporal de encierro, $y$, asimismo, se preparará al recluso para la vida en libertad. Una vez que entro en vigencia el Instituto Nacional Penitenciario (en adelante INP) y la LSPN, sin ser mezquino el sistema penitenciario hondureño dio un giro importante que la comunidad internacional lo vio con buenos ojos, pero es preciso señalar que la $\mathrm{CIDH}$ le planteo al Estado de Honduras, que para que sea efectivo todo ese proceso de transición institucional

\footnotetext{
${ }^{22}$ Véase: Rodríguez Magariños, F.G. "El Derecho Penitenciario”. En R. V, Martínez (Dir.) y otros, Derecho Penitenciario, óp. Cit. p. 44.

${ }^{23}$ Cfr. Rodríguez-Magariños, F.G, (2005) Cárcel electrónica y sistema penitenciario del siglo XXI. Recuperado de: https://core.ac.uk/ download/pdf/58906562.pdf

${ }^{24}$ Art. 87 Constitución de la Republica: Las cárceles son establecimientos de seguridad y defensa social. Se procurará en ellas la rehabilitación del recluido y su preparación para el trabajo.
} 
y normativo, tales funciones deben ir acompañadas de un buen presupuesto que haga operativo el INP Y la LSPN, de lo contrario no habría mayor suceso positivo en el sistema penitenciario ${ }^{25}$.

Es ampliamente conocido que el sistema penitenciario hondureño gira alrededor de un sistema hibrido de cumplimiento de pena, es decir, que el tratamiento penitenciario orbita sobre el sistema progresivo e individualización del tratamiento ${ }^{26}$, el primer principio se refiere que el cumplimiento de la pena se hará de un modo atenuado y flexible hasta llegar a la pre-liberación, y en última instancia a la libertad condicional, y el segundo principio se refiere que de acuerdo a las condiciones personales, sociales del privado de libertad se llevará a cabo su tratamiento penitenciario (ver sistema progresivo e individualización del tratamiento).

Los anteriores, constituyen los parámetros de ejecución de la pena privativa de libertad establecida en la normativa penitenciaria hondureña, en Honduras como en la mayoría de los ordenamientos de Latinoamérica, la ejecución de la pena está a cargo de la administración penitenciaria, el juez de ejecución de la pena solo será una especie de controlador de cómo desarrolle el personal técnico-penitenciario tal ejecución, es decir, que va a controlar y vigilar de cómo se ejecute ${ }^{27}$, asimismo, todo centro penitenciario debe contar con un Consejo Técnico Interdisciplinario así determinado en el artículo 40 de la LSPN, este Consejo es la cabeza central de la ejecución de la pena, es decir, del tratamiento penitenciario progresivo, y las decisiones sobre este aspecto pueden ser controladas por el Juez de Ejecución cuando vulneren derechos.

Hay que tener en consideración y se debe hacer mención al siguiente punto por su importancia, cuando un privado de libertad ingresa a prisión, el Estado es garante sobre esta persona, es decir, que

\footnotetext{
${ }^{25}$ Informe de la Comisión Interamericana de Derechos Humanos, marzo 2013, párrafo 77.

${ }^{26}$ Cfr. Art. 5 Decreto Legislativo 64-2012 Ley del Sistema Penitenciario Nacional.

${ }^{27}$ Art. 3: LSPN: La ejecución de la pena privativa de libertad en todas sus modalidades, debe estar sometida al permanente control y vigilancia del Juez de Ejecución, de conformidad a los descrito en el Código Procesal penal.
}

el Estado entra en una posición de garantía y está en la obligación de garantizar los Derechos Humanos y Constitucionales a los privados de libertad, derechos como la vida, la salud, la alimentación, la educación, la seguridad, etc.

Esto significa que el Estado puede responder nacional e internacionalmente si no garantiza ninguno de los derechos señalados anteriormente, lo anterior se plantea por distintos puntos, como ser la irresponsabilidad del Estado al no garantizar los derechos de los privados de libertad, como por ejemplo, el Estado de Honduras no garantizó la vida de los privados de libertad del centro penitenciario que se incendió en Comayagua, no garantizó la vida de los privados de libertad del centro penitenciario del Porvenir Atlántida, y eso se debió a la falta de políticas públicas holísticas que cumplan parámetros internacionales como la Convención Americana de Derechos Humanos ${ }^{28}$, el no plantear políticas públicas, ha llevado a Honduras a enfrentarse a problemas judiciales de orden internacional.

En fecha 18 de marzo del 2013 la Comisión Interamericana de Derechos Humanos aprobó la versión final del Informe sobre la Situación de las Personas Privadas de Libertad, la CIDH hizo una visita a los principales Centros Penitenciarios de Honduras, donde hizo una exhaustiva evaluación de la situación penitenciaria de aquel momento, donde se encontraron importantes deficiencias estructurales, luego de encontrar tales deficiencias realizó unas importantes recomendaciones; pero lo que plantearemos en dicho apartado es una revisión de lo visto en aquel momento con lo actual, y hacer una revisión de los avances.

Luego que el Relator de los Derechos de las Personas Privadas de Libertad de la CIDH hiciere la correspondiente investigación, encontró graves problemas estructurales que ataña al sistema penitenciario hondureño y que lo han colapsado, entre esas deficiencias estructurales tenemos, la administración penitenciaria como problema estructural, que la misma presenta falta de personal ${ }^{28}$ Informe de la Comisión Interamericana de Derechos Humanos, marzo 2013, párrafo 2. 
capacitado y que el mismo no goza de buen salario, los centros de reclusión presentan problemas de sobrepoblación y hacinamiento, presentan problemas de higiene y salubridad al interno de los mismos, falta de una adecuada provisión y alimentación, asimismo presenta problemas estructurales en cuanto a la delegación del control interno en los propios privados de libertad o también el autogobierno, es decir, un gobierno compartido con los privados de libertad donde se establece que es un mal necesario por la falta de recursos y personal penitenciario, de tal manera que esta es la única forma de mantener el orden al interno del centro penitenciario ${ }^{29}$.

Haciendo un breve recorrido por la situación anteriormente descrita, y viéndola a este año 2019, han sido exiguos los avances mostrados por el Estado de Honduras, por ejemplo, la CIDH en su informe expreso que la creación de Centros Penitenciarios solo es una especie de paño tibio a la problemática penitenciaria en cuanto a los problemas estructurales señalados anteriormente, gozan de plena vigencia en los establecimientos penitenciarios hondureños, por cuanto, los avances son muy, pero muy mínimos en cuanto a esa problemática, por ejemplo, donde si no hay un gobierno compartido, igualmente no hay autogobierno, es en los centros penitenciarios de máxima seguridad, pero en los centros penitenciarios de seguridad media y mínima, como la Penitenciaria Nacional Marco Aurelio Soto, son los propios reclusos que dominan al interior del centro porque el poder está delegado en los coordinadores de cada módulo.

De igual manera, señala el informe de la $\mathrm{CIDH}$ en su párrafo 56, que el Estado de Honduras está en la obligación de proporcionar a los propios reclusos, agua "potable" es decir, que cuando dice potable, es para el consumo humano, instalaciones adecuadas para higiene personal, alimentos suficientes, colchón y ropa de cama adecuada, pero a esta fecha, ninguna de las anteriores recomendaciones cumple el Estado.

Así mismo, para concretizar este último punto, en la condena que se le impuso a Honduras en el caso López Álvarez Vs. Honduras (2006), La Corte IDH, estableció en su sentencia como ${ }^{29}$ Informe de la Comisión Interamericana de Derechos Humanos, marzo 2013, párrafos 27 a, b, 29 (1), 34. medida de no repetición, en el cual, en un tiempo determinado, se debía asegurar a los privados de libertad, una adecuada alimentación, atención médica y condiciones físicas y sanitarias adecuadas que cumplieran con los estándares internacionales de protección a las personas privadas de libertad ${ }^{30}$, todo esto quiere decir, que si alguna persona que se sienta afectada o que este comprometida con los Derechos Humanos de las personas Privadas de libertad denuncie internacionalmente al Estado de Honduras por la situación descrita anteriormente, sería una nueva condena, porque el Estado de Honduras no ha asegurado que los reclusos vivan en condiciones adecuadas a los estándares internacionales.

En conclusión, el Estado de Honduras hablando en un plano general, es muy poco lo que ha hecho desde la aprobación del informe en el año 2013 para llevar condiciones adecuadas de convivencia conforme a las normativas penitenciarias de orden nacional e internacional, de igual manera, quien está a cargo de la administración y funcionamiento de los establecimientos penitenciarios es el INP, y la Ley que rige este sistema concretamente en su artículo 8 , numeral 3, señala que tendrá como atribuciones: velar por la seguridad, atención, custodia, asistencia médica, educativa, laboral, u otros servicios inherentes a los fines de esta Ley, de las personas privadas de libertad a su cargo, en prisión preventiva, cumpliendo penas o medidas de seguridad.

Así como se plantea lo anterior, el Estado violenta tal artículo, porque materialmente no se concreta esta medida de velar por todo lo señalado, y si se hace es una medida muy ínfima de protección de la seguridad, la asistencia médica es altamente deficiente, tanto dentro de los establecimiento penitenciario como el sistema de salud pública para los ciudadanos libres, la educación es deficiente, a lo visto por redes sociales y programas de televisión se está viendo un avance en el trabajo del INP y sus autoridades, pero deben trabajar mucho más fuerte y sobre todo deben trabajar en los problemas estructurales señalados en el informe de la CIDH que de esos puntos no se ve avances sustanciales.

\footnotetext{
${ }^{30}$ Informe de la Comisión Interamericana de Derechos Humanos, marzo 2013, óp. Cit. párrafo 100.
} 
Es importante referirse a las funciones del Consejo Técnico Interdisciplinario (en adelante CTI), este es el encargado de llevar la dirección de la ejecución de la pena privativa de libertad, entre las funciones que lleva a cabo el CTI señaladas en el artículo 41.1 de la LSPN, es determinar la ubicación de los privados de libertad cuando ingresen a prisión, esto se hará de acuerdo a los estudios previos que realicen los profesionales técnicos.

Este mismo CTI entre sus atribuciones o funciones decide la progresión o regresión en grados, el sistema penitenciario hondureño está diseñado en grados, concretamente en régimen de seguridad máxima, media y mínima ${ }^{31}$, y hemos manifestado que uno de los principios por los cuales se va a llevar a cabo la ejecución de la pena privativa de libertad, es por el principio de progresividad, es decir, el avance en los distintos grados, pero este avance solo lo podrá decidir el CTI, así determinado taxativamente en el artículo 41.3 de la $\operatorname{LSPN}^{32}$, esto quiere decir, que si el CTI no autoriza el avance o la regresión en grados de un privado de libertad, esta persona no puede avanzar o regresar de un régimen a otro, solo lo autoriza el CTI de acuerdo a los estudios realizados por todo el personal técnico.

No obstante, el problema central no se ubica ahí, el problema toral que se plantea, es que en la mayoría de los casos no se cumple las directrices de los CTI en cuanto al avance o regresión en grados, porque para trasladar una persona o un grupo de personas de un régimen a otro debe ir con la aquiescencia y autorización del CTI, y los Directores de los establecimientos penitenciarios realizan traslados de un régimen a otro sin haber sido evaluados por el CTI, y sin haber decidido el avance o la regresión en grado de un privado de libertad.

Lo anterior, ocasiona graves consecuencias, en primer lugar, contra el propio recluso, que se le ve interrumpido su programa resocializador, se estila ${ }^{31}$ Articulo 47 Reglamento de la Ley del Sistema Penitenciario Nacional, Decreto Ejecutivo No. 322-2014.

${ }^{32}$ Art. 41.3 LSPN: Decidir el avance o regresión de las personas que estén cumpliendo codena dentro de las diferentes etapas del sistema gradual y progresivo, después de haber evaluado su comportamiento y clasificarlos en los distintos regímenes dentro de los establecimientos que un recluso está en régimen de seguridad media, y el Director del establecimiento penitenciario se le ocurre mandarlo al régimen de seguridad máxima, lo manda sin tomar en consideración los dictámenes u opiniones del CTI, en segundo lugar, lesiona los propósitos que busca el tratamiento penitenciario progresivo, en tercer lugar manda un mensaje negativo a la sociedad que como mensaje no se cumple la Ley por parte de quien se supone la debe cumplir, que es la autoridad penitenciaria, en esencia, esto quiere decir, que los fines de la pena, la prevención especial no cumplirá su propósitos para el cual fue instituido.

\section{CONCLUSIONES}

- Siempre es importante dejar por sentado los aspectos trascendentales que dejo por marcado la historia en cuanto al nacimiento del Derecho Penitenciario, de esa manera se dejó establecido el periplo de lo que una vez se conoció como penología, hasta lo que es hoy el derecho penitenciario y todo el avance dogmático que una vez se tradujo al derecho positivo.

- Sumamente importante el hibrido que representa la ejecución de la pena privativa de libertad, hasta el momento el tema central de ejecución de la pena privativa de libertad lo representa el sistema progresivo y el sistema del tratamiento individualizado, se han planteado otros mecanismos para la ejecución de la pena privativa de libertad, pero hasta el momento no han tenido el suficiente eco como para plantear las reformas en cuanto al tema, sigue vigente el encierro carcelario.

- En esencia, la pena privativa de libertad ha afrontado una serie de críticas, y sobre todo a partir de la década de los setentas que se han incrementado las misma, las estadísticas muestran que los reclusos resocializados son bajos, no llenando las expectativas, por ejemplo, si veinte condenados salen de prisión sin resocializarse, en ese mismo tiempo, están siendo condenados cincuenta privados de libertad, y al final del cumplimiento de la pena de estos, no saldrán 
resocializados, por tanto, únicamente se ve el carácter retributivo de la pena y el fracaso de los fines constitucionales de la pena, dando a entender esto, que la ejecución de la pena privativa de libertad, no cumple los objetivos esperados, en ese sentido, se han propuesto alternativas a la prisión como nuevos modelos de cumplimiento de la pena, sobre todo para penas cortas o de mediano plazo, para ellos, deben estudiarse las posibilidades de una propuesta de lege ferenda para implementar un nuevo modelo de pena para determinados delitos y su cumplimiento y llene las expectativas requeridas. La cárcel electrónica representa una buena alternativa como un modelo emergente al actual sistema carcelario fracasado, en este sistema, el cumplimiento de la pena, se haría extramuros del centro penitenciario, haciendo más fácil la resocialización.

- Honduras dio un paso importantísimo en la implementación del Instituto Nacional Penitenciario y la Ley del Sistema penitenciario Nacional, eso fue un paso importante, y medianamente dentro de sus posibilidades el INP está haciendo buen trabajo, no todo es malo, pero si es importante darle dinamismo, dar soluciones inmediatas a los problemas estructurales que planteo la CIDH en el informe del 2013, dichas problemas estructurales, siguen vivitos $\mathrm{y}$ no se ha visto solución a los mismos, sigue el hacinamiento, sigue la sobrepoblación, sigue la falta de salubridad, sigue la falta de agua potable, sigue el autogobierno o el gobierno compartido en los principales centros penitenciarios, es necesario y urgente que el poder público tome el poder de los establecimientos penitenciarios, esos problemas estructurales desembocan en el fracaso de los fines resocializadores.

\section{BIBLIOGRAFIA}

- Borja Jiménez, E, (2011) Curso de Política Criminal, Valencia Tiran Lo Blanch.

- Constitución de la Republica de Honduras

- Carbonell Mateu, J.C. (1999) Derecho Penal Concepto y Principio Constitucionales, Valencia, Tirant Lo Blanch.

- Cuello Contreras, J., Mapelli Caffarena, B., (2015) Curso de derecho penal PG, Madrid, Tecnos.

- Clases Magistrales, "La Ejecución de la Pena Privativa de Libertad" Universidad de Sevilla, 2015.

- Del Rio Fernández, L., (2016) Manual de Derecho Penitenciario, Agencia Española de Cooperación Internacional, Tegucigalpa, Ediciones San Miguel.

- Deym, J., Crisis actual del sistema penitenciario y de la política penal. Recuperado de http://www. derecho.uba.ar/publicaciones/pensar-en-derecho/ revistas/2/crisis-actual-del-sistema-penitenciarioy-de-la-politica-penal.pdf

- Fernández García, J., El Derecho Penitenciario. Concepto. En Berdugo Gómez de la Torre, Zuniga Rodríguez (Coords) p. 115, Salamanca, Colex.

- Informe de la Comisión Interamericana de Derechos Humanos, marzo 2013

- Ley del Sistema Penitenciario Nacional

- Mapelli Caffarena, B. (2004) Perspectivas actuales de la pena privativa de libertad con especial referencia a la población reclusa extranjera, Revista Centroamericana, Justicia penal y sociedad. Nro. $18,139-160$. 
- Mir Puig, S. (1998) Derecho Penal Parte General, Barcelona, Reppertor.

- Montero Hernanz, T. "El Derecho Penitenciario". En R. V, Martínez (Dir.) y otros, Derecho Penitenciario, pág. 34, Valencia, Tirant Lo Blanch.

- Polaino Navarrete, M., (2015) Lecciones de Derecho Penal PG, Madrid, Tecnos.

- Reglamento General de la Ley del Sistema Penitenciario Nacional.

- Rodríguez-Magariños, F.G, (2005) Cárcel electrónica y sistema penitenciario del siglo XXI. Recuperado de: https://core.ac.uk/download/ pdf/58906562.pdf

- Rodríguez Magariños, F.G. "El Derecho Penitenciario”. En R. V, Martínez (Dir.) y otros, Derecho Penitenciario, pág. 34, Valencia, Tirant Lo Blanch.

- Subijana Zunzunegui, I. J., (2005) El Juez en la ejecución de las penas privativas de libertad. Revista Electrónica de Ciencia Penal y Criminología, RECPC07-11, ISSN 1695-0194. 